\title{
A IMPORTÂNCIA DO ESTUDO DO MEIO NA PRÁTICA DE ENSINO EM GEOGRAFIA FÍSICA
}

\author{
L'MPORTANCE D'ÉTUDE DU MOYEN DANS LA PRATIQUE D'ENSEIGNEMENT \\ DANS LA GÉOGRAPHIE PHYSIQUE
}

\section{LA IMPORTANCIA DEL ESTUDIO DEL MEDIO EN LA PRÁCTICA DE ENSEÑANZA EN GEOGRAFÍA FÍSICA}

\author{
Míriam Aparecida Bueno - UFG - Goiânia - Brasil \\ miriam.cerrado@gmail.com
}

\begin{abstract}
Resumo
Durante muito tempo, em nossa formação e, posteriormente, como professores, convivemos com as críticas aos conteúdos ditos de Geografia Física e os conteúdos ditos de Geografia Humana. Criticava-se o ensino descritivo e fragmentado, apoiado na memorização de nomes e lugares, desconsiderando o processo de ordem natural e social da Geografia. Felizmente hoje encaminhamos a discussão num outro sentido: como trabalhar conteúdos relacionados à natureza e sua importância para o homem? Foi a partir dessa reflexão que, com a disciplina Prática de Ensino em Geografia Física, no curso de Licenciatura da ASMEC/Ouro Fino-MG, por mim ministrada, optei pelo Estudo do Meio como instrumento metodológico para trabalhar na construção dos conceitos geográficos referentes à compreensão da natureza, nesta ciência, reconhecidos como Geografia Física. Entendendo que o aluno não deve ser um sujeito passivo no ensino, limitando-se a adquirir conhecimentos teóricos sem sequer compreendê-los no todo e acreditando que este deve trabalhar extraindo hipóteses e criando sua própria estrutura mental, o trabalho de campo atua como um fio condutor na construção de conhecimentos. Basicamente, justifica-se ao mostrar a importância da integração de saberes propiciados pelas disciplinas escolares para a compreensão/leitura de um mesmo tema, subsidiando na construção do conhecimento.
\end{abstract}

Palavras-chave: Ensino de geografia. Estudo do meio. Metodologias.

\section{Résumé}

Pendant beaucoup de temps, dans notre formation et, ultérieurement, comme enseignants, nous coexistons avec les critiques aux contenus dits de Géographie Physique et les contenus dits de Géographie Humaine. On critiquait l'enseignement descriptif et fragmenté, soutenu dans la mémorisation de noms et de places, en déconsidérant le process d'ordre naturel et social de la Géographie. Heureusement aujourd'hui la discussion marche dans un autre sens: comment travailler contenus rapportés à la nature et son importance pour I'homme? À partir de cette réflexion, avec la discipline Pratique d'Enseignement dans Géographie Physique, en le cours de Licence de ASMEC/Ouro Fino-MG, par moi donné, j'ai opté par l'Étude du Moyen comme instrument méthodologique pour travailler dans la construction des concepts géographiques refférents à la compréhension de la nature, dans cette science, reconnus comme Géographie Physique. En comprenant que l'élève ne doit pas être un sujet passif dans l'enseignement, en se limitant à acquérir des connaissances théoriques sans au moins les comprendre dans tout et en croyant que celui-ci doit travailler en extraire des hypothèses et en créer sa propre structure mentale, le travail de champ agit comme un conducteur dans la construction de connaissances. Basiquement, se justifie montrer l'importance de l'intégration de savoirs rendus propice par les disciplines scolaires pour la compréhension/lecture d'un même sujet, en subventionnant dans la construction de la connaissance.

Mots-clés: Enseignement de géographie. Étude du moyen. Méthodologies. 


\section{Resumem}

Durante mucho tiempo, en nuestra formación y, posteriormente, como profesores, convivimos con las críticas a los contenidos dichos de Geografía Física y los contenidos dichos de Geografía Humana. Se criticaba la enseñanza descriptiva y fragmentada, apoyado en la memorización de nombres y lugares, desconsiderando el proceso de orden natural y social de la Geografía. Felizmente hoy encaminamos la discusión en un otro sentido: ¿cómo trabajar contenidos relacionados a la naturaleza y su importancia para el hombre? Fue a partir de esa reflexión que, con la disciplina Práctica de Enseñanza en Geografía Física, en el curso de Licenciatura de la ASMEC/Ouro Fino-MG, por mí ministrada, opté por el Estudio del Medio como instrumento metodológico para trabajar en la construcción de los conceptos geográficos referentes a la comprensión de la naturaleza, en esta ciencia, reconocidos como Geografía Física. Entendiendo que el alumno no debe ser un sujeto pasivo en la enseñanza, limitándose a adquirir conocimientos teóricos sin siquiera comprenderlos como un todo y creyendo que este debe trabajar extrayendo hipótesis y creando su propia estructura mental, el trabajo de campo actúa como un hilo conductor en la construcción de conocimientos. Básicamente, se justifica al mostrar la importancia de la integración de saberes propiciados por las disciplinas escolares para la comprensión/lectura de un mismo tema, subsidiando en la construcción del conocimiento.

Palabras claves: Enseñanza en geografía. Estudio del medio. Metodologias.

\section{Introdução}

Durante muito tempo, em nossa formação e, posteriormente, como professores, convivemos com as críticas aos conteúdos ditos de Geografia Física e os conteúdos ditos de Geografia Humana. Criticava-se o ensino descritivo e fragmentado, apoiado na memorização de nomes e lugares, desconsiderando o processo de ordem natural e social da Geografia. Felizmente hoje, encaminhamos a discussão num outro sentido: como trabalhar conteúdos relacionados à natureza e sua importância para o homem?

Os PCN's de Geografia trazem essa proposta claramente quando, no eixo 2 - o estudo da natureza e sua importância para o homem - enfoca os fenômenos naturais, sua regularidade e possibilidade de previsão pelo homem, e a natureza e as questões socioambientais. É importante para o aprendizado que o aluno possa construir raciocínios lógicos sobre as leis que regulam o universo dos fenômenos naturais, reconhecendo a relevância desse conhecimento, não só para a continuidade do avanço das ciências da natureza, mas também para a sua vida prática.

Suertegaray (1999, p. 57) discute algumas idéias, oriundas de sua prática como professora. Certa vez, questionada sobre o que ensinar em Geografia Física, iniciou uma reflexão a partir de alguns elementos:

A Geografia, como ciência e a Geografia como disciplina a ser ministrada no $1^{\circ}$ e $2^{\circ}$ graus, deve expressar-se através de um método que seja indissociável, ou seja, é necessária a busca de um caminho unitário entre a dinâmica da natureza e da sociedade. 
O caminho escolhido é uma opção do professor/pesquisador/educador de acordo com a sua perspectiva teórico-pedagógica de ensino-aprendizagem e posição frente ao mundo. Este caminho se expressa naquilo que é denominado método de ensino. [grifo nosso]

Sendo o método uma opção refletida, o conteúdo a ser ensinado é resultado de uma interação entre sujeito (professor) e objeto (conteúdo a ser selecionado), portanto, algo resultante da construção do sujeito.

E foi nessa perspectiva que conduzimos a disciplina de Prática de Ensino em Geografia Física, junto ao grupo de alunos da Faculdade ASMEC, em Ouro Fino-MG, no ano de 2007.

O curso de Geografia daquela Faculdade, recentemente aprovado pelo MEC, recebe alunos de diferentes municípios, não só do estado de Minas Gerais (Santa Rita de Caldas, Ibitiúra de Minas, Jacutinga, Pouso Alegre, Borda da Mata, Bueno Brandão, Cambuí, Cachoeira de Minas, São José do Alegre, Piranguçu e Ouro Fino) mas também do estado de São Paulo (Piracicaba, Mogi Mirim, Mogi Guaçu, Itapira, Águas de Lindóia, Pinhalzinho e Campinas). São pessoas com diferentes histórias de vida e de luta. Alguns já são professores, outros nunca se viram diante de uma sala de aula, na qualidade de docente.

A proposta da disciplina foi apresentada, visando resgatar a fundamentação teórica já trabalhada na disciplina anterior, de Prática de Ensino em Geografia Humana, onde havíamos trabalhado com o estudo do meio, a partir de uma perspectiva socioconstrutivista.

O estudo do meio é um tipo de atividade escolar que pode estar vinculado a uma atividade de pesquisa mais ampla, quando se constitui uma de suas etapas, ou pode ser desenvolvido como um procedimento específico para tratamento de conteúdos de Geografia.

Segundo Cavalcanti (2002, p. 91), trata-se de:

...um procedimento que tem uma longa tradição nas práticas de ensino em geral e, em particular, nos estudos geográficos na escola, dada sua característica de lidar com o meio... entendendo o meio como um processo de interrelação da natureza e da sociedade.

Feltran e Feltran Filho (1991), apud Cavalcanti (2002, p. 90), fazem a seguinte colocação:

Estudar o meio, o meio-ambiente, a realidade, a vida (ou qualquer que seja o vocabulário escolhido) significa tentar encontrar elementos para melhor compreender a interação do homem com o mundo, o que se faz a partir de determinado ponto de vista ou enfoque teórico. 
O estudo do meio propicia o contato direto do aluno com seu meio imediato, exercitando a intuição através de trabalhos de campo e excursões. Tratase de um método ativo e interativo por requerer um trabalho interdisciplinar.

Seu objetivo no ensino é o de mobilizar, em primeiro lugar, as sensações e percepções dos alunos no processo de conhecimento para, em seguida, proceder-se à elaboração conceitual.

Considerando que a elaboração conceitual deve ser a preocupação do professor em sala de aula, pode-se pensar na construção de conceitos, a partir dos conhecimentos prévios dos alunos, levando-os à elaboração do conceito científico, realizando assim, uma transposição didática.

O estudo do meio requer um planejamento de forma a garantir o cumprimento de suas etapas essenciais, que segundo Cavalcanti (2002, p. 91), são:

1. a preparação: é importante a mobilização do aluno, a problematização do conteúdo, o contato com alguma representação do meio a ser estudado (textos, mapas, fotos).

2. a realização do trabalho: consiste na observação, registro, descrição e coleta de informações.

3. exploração do trabalho em sala de aula: o retorno à sala de aula é bastante importante, pois a partir da síntese e da exposição dos resultados pode-se dar continuidade à atividade.

Para Ogallar (1995), apud CAVALCANTI (2002, p. 92), esse procedimento adequa-se ao estudo de Geografia pois:

- favorece a conceitualização geográfica

- permite o desenvolvimento de destrezas procedimentais relacionadas com a medição de distâncias, alturas, freqüências, etc

- desenvolve a capacidade de observação

- permite a elaboração de visões integradas de aspectos convencionalmente tratados de modo separado no ensino

- propicia a comparação, identificação e semelhanças e diferenças entre paisagens

- permite uma perspectiva ambiental sobre o entorno e em busca de soluções aos problemas ambientais

- constitui um marco único para o desenvolvimento de destrezas cartográficas. 
Assim, a disciplina foi encaminhada para resgatar a discussão sobre o estudo do meio e, a partir dele, fundamentados pelos Parâmetros Curriculares Nacionais (1997), desenvolver atividades práticas - oficinas pedagógicas - com o objetivo de levar os alunos à construção de conceitos em Geografia Física.

Esse artigo visa apresentar essa experiência, inseri-la num processo de discussão e permear o papel do professor e do aluno em um determinado contexto.

\section{A metodologia utilizada}

O estudo da paisagem em um trabalho de campo, fora da sala de aula, desenvolve a capacidade de compreensão de características locais, regionais, nacionais e globais. Todo o lugar tem características próprias que lhes dão significado e forma. As características "físicas" e "humanas" dos lugares, estudadas em conjunto, oferecem guias para auxiliar os alunos a entender a natureza e sua importância para o homem.

O meio em que cada um vive é a concretização das forças que regem o mundo atual. É a partir do estudo do meio que se pode perceber a obra dos homens no espaço e no tempo e, também, se perceber como sujeito. Tendo em vista que uma forma de compreender as inter-relações entre os diversos aspectos do meio e das atividades sociais é, inicialmente, através de um diagnóstico socioambiental de uma região específica, definiu-se, inicialmente, a seguinte metodologia:

1. Delimitação do espaço a ser estudado e diagnosticado: os alunos se organizaram em grupos e definiram esse espaço, escolha que estava vinculada ao município onde moravam e de onde eles resolveram partir, da definição de uma situação-problema. Foram eles: Bueno Brandão, Ibitiúra de Minas, Ouro Fino e Itapira.

2. Levantamento dos conhecimentos prévios dos alunos sobre o espaço e o tema escolhido:

- O turismo ecológico em Bueno Brandão/MG

- A agricultura do café em Ibitiúra de Minas/MG

- O abastecimento de água em Ouro Fino/MG

- O ambiente urbano, a indústria e o modo de vida em Itapira/SP 
3. Planejamento e organização dos aspectos da realidade que seriam levantados para o diagnóstico socioambiental da área escolhida:

- Atividades econômicas desenvolvidas na área (agropecuária, indústria, comércio, serviços)

- Habitação (caracterização)

- Relevo e solos (forma de utilização)

- Recursos hídricos (utilização)

- Clima (caracterização e alterações)

- Vegetação (identificação e utilização)

- Alterações socioambientais

Esses dados foram sistematizados em relatórios de observação, registro, transcrição de entrevistas e tabulação dos dados quantitativos.

Concluída essa primeira etapa de registro e análise dos dados coletados, partiu-se para a etapa seguinte: buscar, junto aos PCN's, o eixo temático no qual o tema abordado poderia ser inserido. Seguindo a estrutura apresentada nos PCN's, definiu-se o eixo e o tema, como mostrado no quadro abaixo.

\begin{tabular}{|c|c|}
\hline Tema do estudo do meio & Eixos temáticos dos PCN's \\
\hline $\begin{array}{l}\text { O turismo ecológico em Bueno } \\
\text { Brandão/MG }\end{array}$ & $\begin{array}{l}\text { Eixo: O campo e a cidade como formações socioespaciais } \\
\text { Tema: A modernização capitalista e a redefinição nas relações en- } \\
\text { tre o campo e a cidade }\end{array}$ \\
\hline $\begin{array}{l}\text { A agricultura do café em Ibitiú- } \\
\text { ra de Minas/MG }\end{array}$ & $\begin{array}{l}\text { Eixo: O campo e a cidade como formações socioespaciais } \\
\text { Tema: A cultura e o consumo: uma nova interação entre o campo } \\
\text { e a cidade }\end{array}$ \\
\hline $\begin{array}{l}\text { O abastecimento de água em } \\
\text { Ouro Fino/MG }\end{array}$ & $\begin{array}{l}\text { Eixo: O estudo da natureza e sua importância para o homem } \\
\text { Tema: A natureza e as questões socioambientais }\end{array}$ \\
\hline $\begin{array}{l}\text { O ambiente urbano, a indústria } \\
\text { e o modo de vida em Itapira/SP }\end{array}$ & $\begin{array}{l}\text { Eixo: Modernização, modos de vida e a problemática ambiental } \\
\text { Tema: Ambiente urbano, indústria e modo de vida }\end{array}$ \\
\hline
\end{tabular}

A partir dessas definições, prosseguiu-se com a metodologia:

4. Levantamento dos conceitos geográficos a serem trabalhados nas oficinas pedagógicas: tendo sido definidos os eixos e os temas, procedeu-se à análise dos conceitos geográficos que poderiam ser trabalhados durante a oficina pedagógica. Foram elaborados mapas conceituais e a partir deles, evidenciados os conceitos abaixo relacionados: 


\begin{tabular}{|l|l|}
\hline \multicolumn{1}{|c|}{ Tema do estudo do meio } & \multicolumn{1}{c|}{ Conceitos geográficos } \\
\hline $\begin{array}{l}\text { O turismo ecológico em Bueno } \\
\text { Brandão/MG }\end{array}$ & $\begin{array}{l}\text { Cachoeira, turismo, ecológico, água, lazer, economia, consciência } \\
\text { ambiental }\end{array}$ \\
\hline $\begin{array}{l}\text { A agricultura do café em Ibitiú- } \\
\text { ra de Minas/MG }\end{array}$ & $\begin{array}{l}\text { Agricultura, paisagem rural e urbana, agricultura de subsistência } \\
\text { e comercial, cultura perene e temporária, meio ambiente, polui- } \\
\text { ção, bóia-fria, curva de nível, transporte }\end{array}$ \\
\hline $\begin{array}{l}\text { O abastecimento de água em } \\
\text { Ouro Fino/MG }\end{array}$ & $\begin{array}{l}\text { Bacia hidrográfica, assoreamento, abastecimento, preservação, im- } \\
\text { portância da água, tecnologia, relação homem x natureza }\end{array}$ \\
\hline $\begin{array}{l}\text { O ambiente urbano, a indústria } \\
\text { e o modo de vida em Itapira/SP }\end{array}$ & $\begin{array}{l}\text { Industrialização, urbanização, mecanização, cidade, poluição, mi- } \\
\text { gração, energia, reciclagem, educação ambiental }\end{array}$ \\
\hline
\end{tabular}

5. Verificação das possibilidades de integração com as outras disciplinas escolares: Português, Matemática, História, Ciências e Arte. Nesse momento, os grupos buscaram distribuir, entre as disciplinas trabalhadas na escola, as propostas interdisciplinares.

6. Definição dos materiais didáticos (maquetes, painéis, coletânea de fotografias, etc.) a serem confeccionados pelo grupo, para serem apresentados durante as oficinas pedagógicas.

\section{As oficinas pedagógicas}

Essa atividade consistiu no momento de avaliação da disciplina, onde os alunos puderam "materializar", de forma bastante criativa, todo o trabalho realizado durante a Prática de Ensino.

Foram apresentados trabalhos escritos com o histórico metodológico da atividade, desde os procedimentos realizados para o estudo do meio, a definição de vínculo com os PCN's e a relação dos conceitos geográficos a serem trabalhados. Foi redigida, também, uma justificativa para o trabalho com as oficinas pedagógicas, os objetivos, a metodologia e os materiais utilizados.

Nas considerações finais, cada grupo apresentou seus comentários pessoais a respeito de todas as atividades. 
Oficina 1: O Turismo Ecológico em Bueno Brandão - MG.
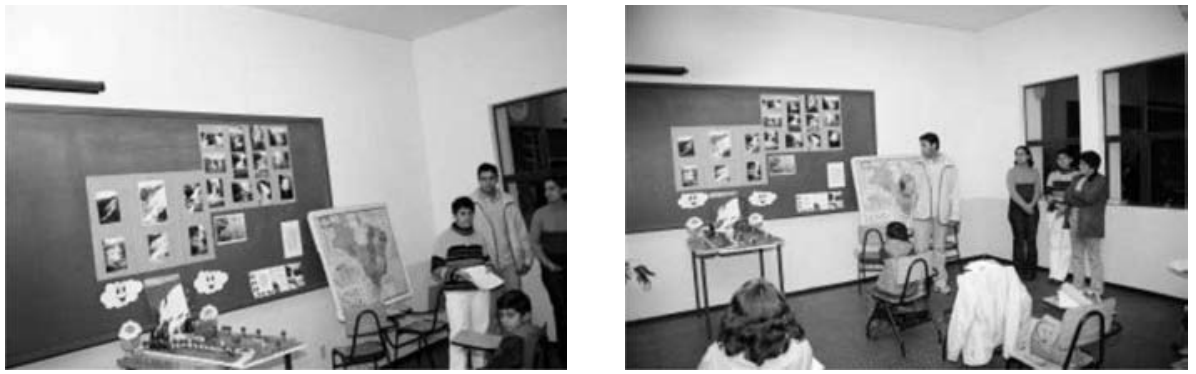

Grupo formado por Maria Clara, Izabel, Clarice e Daniel.

Foto: André A. Pedro, junho de 2007.

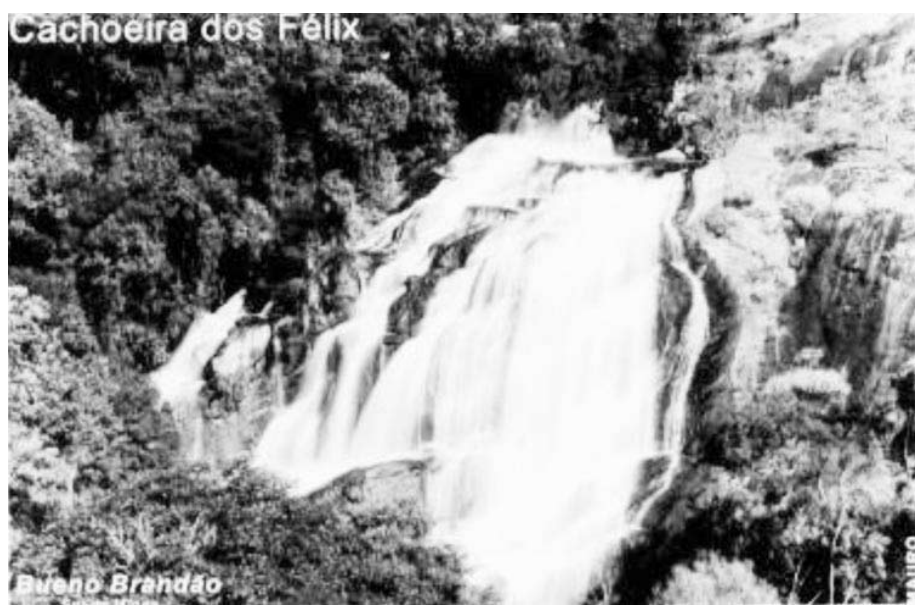

Cachoeira dos Felix - escolhida pelo grupo para o estudo do meio, representada na maquete e nos painéis fotográficos acima.

Fonte: CD Rom com informações turísticas de Bueno Brandão.

A iniciativa de implantação do turismo ecológico em Bueno Brandão é recente, o que vem chamando a atenção de turistas de outros estados. Essa atividade contribui para o desenvolvimento econômico do município, mas ao mesmo tempo tem trazido significantes impactos ambientais. Conhecida como a Cidade das Cachoeiras, é uma região montanhosa com picos de até $1750 \mathrm{~m}$ acima do nível do mar, entrecortada por vales caracterizados por mata nativa. 


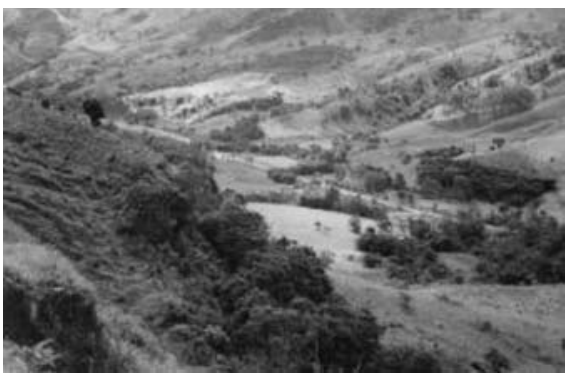

Vista do Vale das Furnas, 2007.

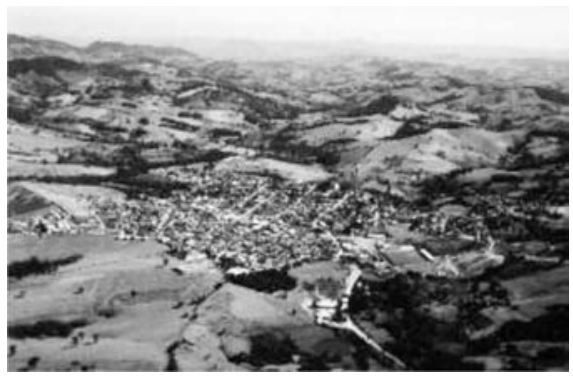

Vista parcial da cidade de Bueno Brandão - MG, 2007.

Partindo de uma situação-problema, através do estudo do meio pode se desenvolver, além dos conceitos geográficos elencados, a formação crítica do aluno em relação à degradação e exploração indiscriminada dos recursos naturais.

Oficina 2: A agricultura do café em Ibitiúra de Minas - MG.
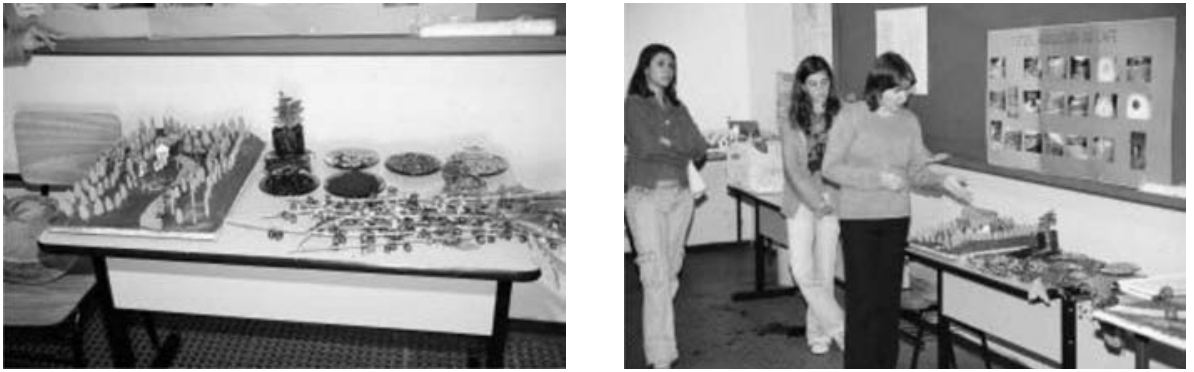

Grupo formado por: Ana Maria, Celina, Ivone, Milene, Sandra e Suzana.

Foto: André A. Pedro, junho de 2007.

Em Ibitiúra de Minas, o cultivo do café ainda é a principal atividade econômica do município. O trabalho é desenvolvido através da agricultura familiar. Os agricultores demonstraram cuidados com o ambiente, organizando a plantação em curvas de nível para evitar o processo erosivo, mantendo as matas ciliares para proteção das nascentes. 


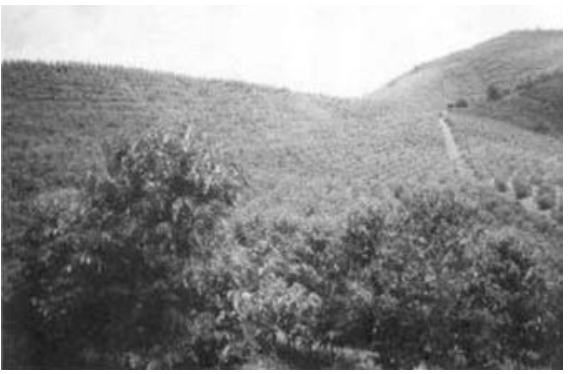

Vista parcial de uma plantação de café.

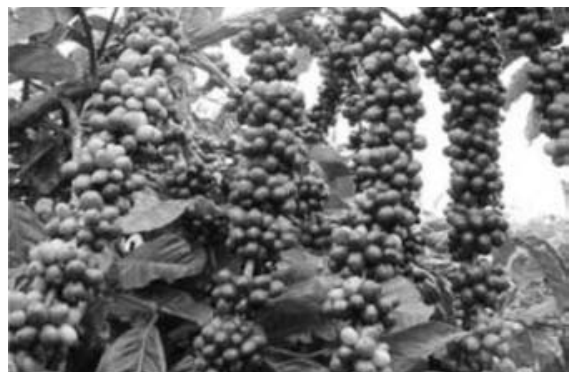

Sementes de café.

Esse estudo do meio permitiu ao grupo identificar o modo de vida da população rural, especificamente daqueles produtores ligados à cultura do café, atividade geradora de renda para o município. Destacou-se a ligação dessa atividade com a natureza, preocupação presente no trabalho dos agricultores. O trabalho mostrou também as técnicas utilizadas, manuais ou mecanizadas, na agricultura do café.

A maquete contribuiu para demonstrar uma plantação de café, com explicações sobre curvas de nível, cuidados com o solo e assoreamento do rio. O mural de fotos mostrou a lavoura de café, o terreiro para secagem dos grãos, a tulha onde o café é armazenado para posterior beneficiamento, o trabalho dos agricultores e os instrumentos utilizados nesse tipo de lavoura.

Durante a realização da oficina foram demonstradas as várias fases do café: em muda, café verde, café em coco (seco), café limpo (beneficiado), café torrado e moído e café preparado, pronto para saborear.

Oficina 3: O abastecimento de água em Ouro Fino - MG.
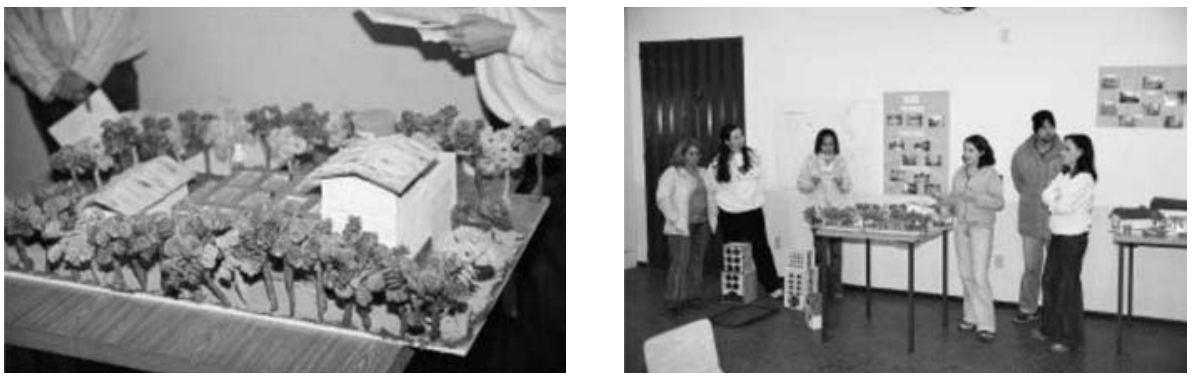

Grupo formado por: Giancarlo, Juliana Helal, Juliana Oliveira, Lidiana, Maiza e Silvia.

Foto: André A. Pedro, junho de 2007. 
O abastecimento de água pelo DMAAE é feito desde 1991, mas desde 1978 a cidade de Ouro Fino possui água tratada, serviço que era realizado pelo SAAE. A captação na cidade é feita por gravidade e por bombeamento, com pequenas barragens. Toda água vem da Bacia do Rio Mogi. A distribuição da água é feita por gravidade à partir das caixas d’água do DMAAE e atende a todas as famílias da cidade. É feito também um trabalho de conscientização da população sobre a importância da preservação da água.

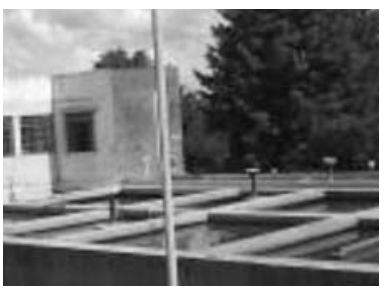

ETA - Ouro Fino.

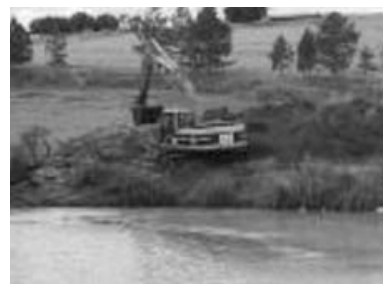

Represa Zezé de Matos.

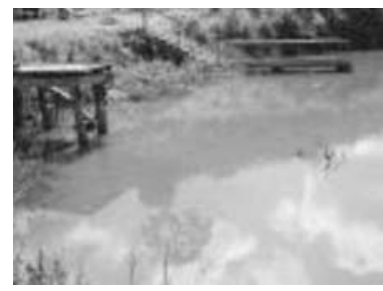

Captação de água.

Fotos: Lidiana Barbosa: junho de 2007.

A maquete confeccionada pelo grupo foi doada ao DMAAE, a pedido do responsável pelo local. Este setor recebe inúmeras visitas de alunos de escolas do município, e encontraram na maquete um excelente recurso didático para fazer as devidas explicações.

Oficina 4: O ambiente urbano, a indústria e o modo de vida em Itapira/SP.
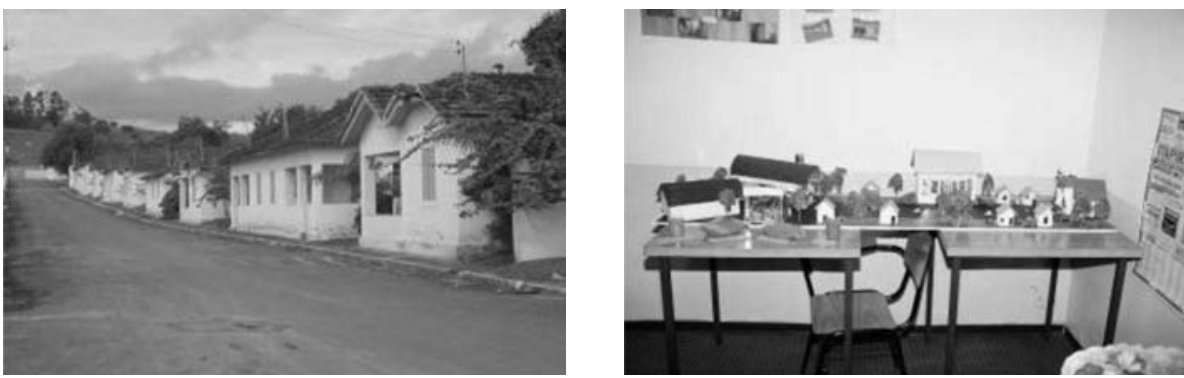

Usina de açúcar e álcool Virgolino de Oliveira - vila dos funcionários (espaço real e sua representação). Foto: André A. Pedro, junho de 2007 
Essa usina é de grande importância para o município de Itapira, não só nos aspectos econômicos, mas sociais e culturais também. Nos aspectos econômicos considera-se a geração de empregos e o faturamento nos impostos recolhidos pelo município. No aspecto social, a administração contribui com doação de roupas e cobertores aos funcionários, bem como auxilia entidades públicas. No aspecto cultural, incentiva os funcionários a dar continuidade aos seus estudos. Possui uma escola que oferece Educação para Jovens e Adultos, cursos técnicos, bem como palestras sobre diferentes temas de interesse da comunidade local.
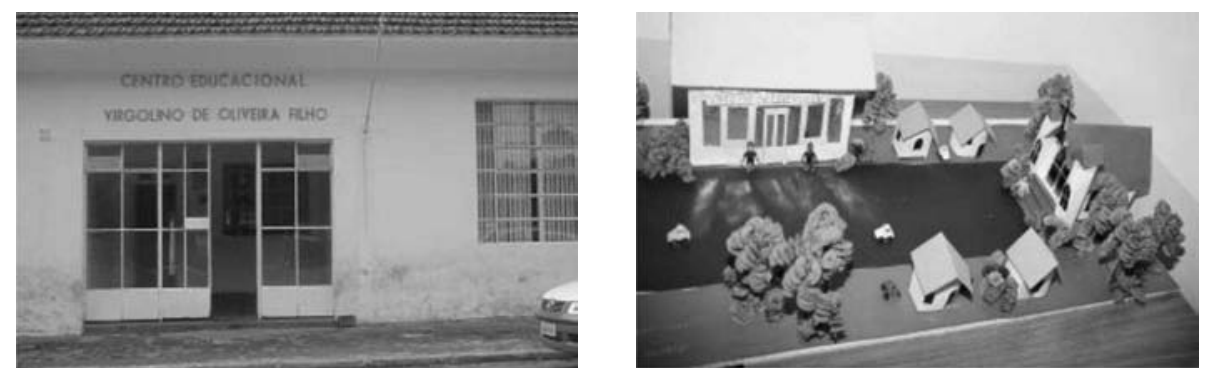

Escola da Usina (o real e sua representação).

Fotos: André A. Pedro, junho de 2007.

Durante o estudo do meio, o grupo entrevistou o engenheiro responsável e observaram todo o espaço da usina, o solo, a usina de modo geral, a plantação da cana-de-açúcar, o rio, a reposição de árvores e o reaproveitamento da vinhaça para adubação do próprio solo.
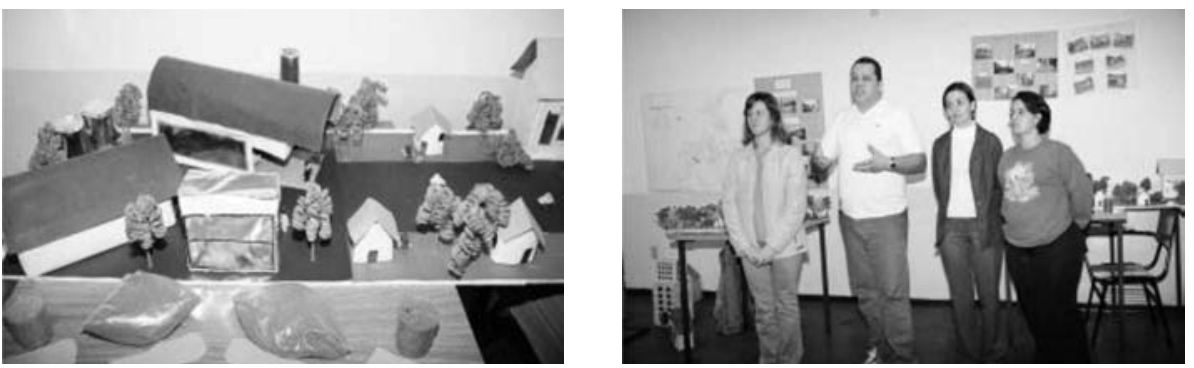

Grupo formado por: André, Andréia, Fabiana, Gislaine e Lizamara.

Foto: André A. Pedro, junho de 2007. 


\section{Considerações finais}

Apesar de tratar-se de um relato de uma experiência realizada em sala de aula, o presente artigo traz consigo uma proposta de inserir essas práticas docentes num contexto maior de discussão sobre formação de professores. Penso que, atendendo às diretrizes curriculares, as disciplinas de Prática de Ensino devem priorizar a legítima formação do professor. O encaminhamento para essa discussão deve ser o de: que professores de Geografia queremos formar, para qual escola e para qual sociedade?

Os nossos professores de Geografia precisam de uma sólida formação integral, científica e humanista. Para Vesentini (2002, p. 239), a orientação para um curso de Geografia que pretenda formar bons profissionais (docentes ou não), é:

...ter um adequado curso básico: que seja pluralista e contemple as diversas áreas e tendências da ciência geográfica; que esteja voltado não para produzir especialistas e sim para desenvolver nos alunos a capacidade de "aprender a aprender", de pesquisar, de observar, de ler e refletir, de desconfiar de clichês ou estereótipos, de ter iniciativa e capacidade próprias.

A proposta de se trabalhar os conteúdos da Geografia Física, sem enfatizar a dicotomia, a partir de um estudo do meio me parece pertinente.

Entendendo que o aluno não deve ser um sujeito passivo no ensino, limitando-se a adquirir conhecimentos teóricos sem sequer compreendê-los no todo e acreditando que este deve trabalhar extraindo hipóteses e criando sua própria estrutura mental, o estudo do meio atua como um fio condutor na construção de conhecimentos. Basicamente, justifica-se ao mostrar a importância da integração de saberes propiciados pelas disciplinas escolares para a compreensão/leitura de um mesmo tema, subsidiando na construção do conhecimento.

Levar os alunos para um passeio ou lanche num parque, ou mesmo numa praça, e conversar sobre a experiência, sobre o que sentem em tais lugares, sobre o significado desses espaços. São exemplos de atividades que, mesmo sem a complexidade e a densidade de um estudo do meio, também podem ser realizadas. 


\section{Referências}

ARCHELA, R. S. Geografia para o ensino médio: manual de aulas práticas. Londrina: UEL, 1999.

BRASIL. Secretaria de Educação Fundamental. Parâmetros Curriculares Nacionais de Geografia. Brasília: Ministério de Educação e do Desporto - SEF. 1997.

CARLOS, Ana Fani Alessandri (Org.). A Geografia na Sala de Aula. São Paulo: Contexto, 1999.

CASTROGIOVANI, A. C. Ensino de geografia: práticas e textualizações no cotidiano. Porto Alegre: Mediação, 2000.

Geografia em sala de aula: práticas e reflexões. Porto Alegre: UFRGS, 1999.

CAVALCANTI, Lana de Souza. Geografia, escola e construção de conhecimentos. Campinas-SP: Papirus, 1998.

. Geografia e práticas de ensino. Ed. Alternativa: Goiânia, 2002.

OGALLAR, A. S. El trabajo de campo y lãs excursiones. In: JIMENEZ, A. M. Ensenhar Geografia, de la teoria à la práctica. Madrid: Síntesis, 1995.

OLIVEIRA, A. U. e PONTUSCHKA, N. N. Geografia em perspectiva. São Paulo: Contexto, 2002.

SUERTEGARAY, D. M. A. O que ensinar em Geografia (Física)? In: Geografia e educação: Geração de Ambiências. Porto Alegre: UFRGS, 1999.

VESENTINI, J. W. A formação do professor de Geografia: algumas reflexões. In: OLIVEIRA, A. U. e PONTUSCHKA, N. N. Geografia em perspectiva. São Paulo: Contexto, 2002.

Míriam Aparecida Bueno - Professora Adjunta da Universidade Federal de Goiás. 